\title{
Verdad y engaño en mitos ayacuchanos
}

Juan Ansión

EL DISCURSO MITICO andino tiene una lógica interna que es preciso apreciar y conocer. Tiene la coherencia de un lenguaje que expresa una realidad vivida. La reciprocidad es uno de los principios rectores de la vida económica y social del campesino: también es un elemento central de los relatos míticos andinos. Si la vida social, particularmente en los Andes, supone el respeto de las reglas de reciprocidad, la ruptura con éstas conduce a la separación de la sociedad, reduce al estado animal y al mundo de la noche $y$ de la anticultura.

En un trabajo anterior ${ }^{1}$ habíamos visto que la mentira era una de las expresiones de la ruptura de reciprocidad. En esta oportunidad, trataré de precisar este análisis a partir de algunos textos que nos hablan del engaño y de la verdad. Esto nos llevará a algunas reflexiones sobre los malentendidos y problemas que pueden surgir entre el científico social y sus informantes, como resultante del encuentro entre las normas que rigen el quehacer científico, y aquellas que prevalecen en el mundo andino.

\section{Cabezas voladoras:}

\section{el antisocial engañado}

Empezaré por presentar algunos textos que nos hablan de un mismo personaje, la uma o cabeza.

El primero de ellos ${ }^{2}$ fue presentado en 1981 por Eloida Allcca Choccña, estudiante de la, Escuela Normal Superior de Ayacucho. Ella lo escuchó de su padre, Modesto Allica Roca, quien ubicó los hechos relatados, en el distrito de Apongo, en Víctor Fajardo. 


\section{Uman Taqtaq}

"Esto acontece en Sucahuaycco. Son nombres peculiares de algun os lugares. Cuenta que un día, muy de madrugada, una 'cabeza voladora' encontró en su trayecto a un viajero y se posó sobre su hombro. El hombre parecía conocer la psicología de estos sujetos. Siguió su camino y formaban dos cabezas. Avanzaban . . . La cabeza era de una mujer. Pasado un buen trecho llegaron a un lugar cultivado de higueras, y de ellas colgaban unos higos que decian: ¡Comedme! Entonces el hombre le dijo al uman taqtaq: 'Oh, iqué ricos higos! ... Voy a cogerlos para comer. Esperáme, recojo y vuelvo'.

La cabeza consintió, se desprendió y sobre las ropas del viajero se sentó al pie del árbol esperando. Por tanto el suje to cogía y cogra. Entonces, aparece un venado y tomó posición, y el inocente de lo asustado, más se sorprendió y emprendió veloz carrera. Mientras ella gritaba ibuuu! ihuac ... huac!, tomando rumbo hacia el monte. Y el viajero bajó rápido del árbol y también emprendió velozmente a buscar re. fugio para no toparse más con viajeros misteriosos".

La cabeza voladora es uno de estos seres temibles y misteriosos que atacan a los viajeros aislados durante la noche ("muy de madrugada"). El texto nos dice que la cabeza pertenece a una mujer, y que su nombre quechua es uman taqtaq. Según Clodoaldo Soto ${ }^{3}$, el verbo taqtay significa vaciar, echar, verter; botar cosas no liquidas de un recipiente. El uman taqtaq sería entonces la persona que "bota" su propia cabeza, que se quita la cabeza. Es pues una cabeza que ha dejado su cuerpo en algún sitio.

El objetivo de la uma es posarse sobre el hombro de su victima. De manera similar, "toma posición" en el venado. Aunque no se diga aquí explicitamente, está claro que resulta así una carga para quien ha sido agarrado. Probablemente, al posarse sobre el hombro no sólo toma posición sino también posesion. El castellano de la zona, según mi experiencia, no distingue claramente entre ambas palabras, ni verbalmente, ni tampoco por escrito, pues se escribe muchas veces una palabra por otra. Esto quizá nos indique que posicionarse en es también posesionarse de, y vice-versa. Esta interpretación nos permitiría entender por qué la uma se sienta sobre las ropas del viajero: de esa manera sigue siendo dueña del hombre (recordemos que para hacer daño a una persona, al brujo le basta tener una prenda de la victima).

El grito de la cabeza nos recuerda la bulla que hacen los gentiles en noches sin luna, según uno de los textos de nuestro artículo anterior (1982). Como también actúa de noche, es posible que el uman taqtaq tenga rasgos comunes con estos abuelos.

Veamos ahora el asunto del engaño mismo. Existe sin duda premeditación, pues "el hombre parecía conocer la psicología de estos sujetos". El texto no explica por qué la cabeza accede tan fácilmente a soltar al hombre. 
La única explicación posible es que ella sacará alguna ventaja de esta situación, es decir que el hombre coge los higos para ella, sea para dárselos directamente, sea porque le conviene que el hombre se alimente bien, pues ella vivirá de él como un parásito. Lo que es más curiosọ, es que se deje engañar por el venado. En otras versiones reproducidas abajo, el venado aparece corriendo y ésta sería la razón de la confusión. Pero en verdad, ninguna persona normal confundiría a un hombre con un venado, aún corriendo. Hay otra explicación: la cabeza confunde a los hombres con los animales, del mismo modo como lo hace Vivucha (véase nuestro artículo anterior - 1982), aquel niño ladrón y ocioso que se había ido a vivir en una cueva en la montaña, desde donde asaltaba y mataba a los caminantes, y que "ponía distintas cabezas de animales en el cuerpo humano".

$\mathrm{Al}$ igual que Vivucha, la cabeza voladora ha roto con la sociedad, como lo indica también la huida hacia el monte; $y$ al pertenecer al mundo de la naturaleza no es capaz de reconocer a los verdaderos seres sociales. Quiza, olvidándose del cuerpo y medrando de los demás, no tiene lugar en la sociedad. Para vivir en ella, el hombre no puede reducirse al intelecto. ¿Qué haría pues en el campo alguien que no sepa trabajar con sus manos, ni use su corazón para compartir y colaborar con los demás?.

Enfrentado a un ser de esta naturaleza, el viajero tiene derecho a engañarle para lograr su libertad. Y la manera de hacerlo es utilizando la contradicción de la uma: al aservir al hombre, ésta necesita hacerlo trabajar, pero para cumplir con su dueña el hombre tiene que ser provisionalmente soltado.

Queda una pregunta pendiente: ¿por qué la cabeza no puede subir con su esclavo el árbol? La respuesta es posiblemente obvia para el destinatario de la zona que conoce bien las características de las cabezas voladoras, pero prefiero dejar la pregunta pendiente y presentar de inmediato el segundo texto que nos aclarará al respecto.

El siguiente texto fue presentado en 1981 por Victor Santa Cruz Miranda, en el marco de un curso de la Universidad Nacional de San Cristóbal de Huamanga, como producto de una entrevista a Albino Morales, natural de San Miguel, de 48 años.

\section{El Aya Uma}

"Esta versión se refiere al aya uma que significa en nuestros medios, la cabeza de un ser humano desprendida del cuerpo. Esto está relacionado con la bruja.

- ¿Usted podría contarnos algo del aya uma?

- Te diré que sé por referencia algunas cosas, y he escuchado hablar hace años. Di- 
cen que el aya uma o uma se desprende del cuerpo de una mujer, en este caso de la bruja, y dicen que la cabeza se desprende los dias señalados (martes y viernes) a las doce de la noche. Un día dice que la bruja se habra desprendido de su cuerpo y para esto la parte contraria de esta bruja a la parte del cuello que se desprendió, lo pusie. ron cenizas y lo dejaron así. La ceniza solian poner para que el uma o aya uma no pudiera pegarse a su cuerpo de la bruja; ya que la bruja salía a dar vueltas lanzando quejidos extraños.

$Y$ dicen también que cuando el aya uma no encuentra agua y ve algunas personas en su camino la persigue hasta darle alcance: y luego de un salto se le pega en el cuerpo y queda como si la cabeza fuera parte del cuerpo de esa persona.

Tal es así, dicen, que en el camino de San Miguel hacia la Selva un hombre viajaba con su equipaje. en esos momentos se le prendió el aya uma o uma de tal manera quedando el hombre asombrado y vergonzoso de tener dos cabezas. Ya eran más o menos las 4 de la mañana y era noche de luna, al hombre se le ocurre descansar y en esos sitios habra plantaciones de manzanos, y en eso se le viene una gran idea en la que le ruega al uma a que se baje para que suba a la manzana y asi cogerla y darle al uma. Así el uma acepta. El hombrecito subió a la manzana, en esos momentos se presentó un venado a gran velocidad, el uma pensando que era el hombre que se estaba fugando se prendió al venado y se fueron descarriados hacia el monte. De esta manera quedando el hombrecito libre.

- ¿Podria Usted contarme algo más del aýa uma?

- También dicen que es costumbre en esos lugares de agarrar la cabeza de bruja o el aya uma, lo agarran con la punta del cuchillo navaja o en otro caso con espinas. $Y$ le cortan el pelo para que al dia siguiente le puedan conocer facilmente. El uma para esto le ruega a la persona que haya hecho esto para que no le avisen a nadie, y así ofreciéndole muchas riquezas".

El presente texto confirma nuestro análisis anterior.

En el episodio similar aparece claramente que el hombre sube al árbol para cogerle fruta a la uma. Los higos han sido reemplazados por manzanas, lo que indica que la naturaleza de la fruta no es significativa. También aparece cl venado corriendo ("a gran velocidad"), como se adelantó anteriormente.

El texto es interesante porque aporta clementos nuevos de explicación. La cabeza de mujer pertenece a una bruja. cosa que no es extraña por todo lo que ya sabíamos de ella. Ava Sin embargo se sabe que la bruja no es una persona muerta, no es un conde. nado. ¿Por qué entonces tal denominación? Es posible que el narrador quiera expresar asi que la bruja, ente de la noche y del maleficio, pertenece al mundo de la muerte, aún en vida. Sería como un cadáver viviente, desde el punto de vista de la sociedad. Asi como para los seres antisociales se borra la distinción entre cultura y naturaleza, también se confundira para ellos la vida y la muerte, por haber muerto socialmente. Otra explicación, no contradictoria con la primera, es que el al'a designe al cuerpo inanimado de la bruja que queda como cadaver mientras su cabeza vuela. 
El texto nos enseña que no sólo se engaña a la uma en una situación defensiva: también se puede tomar la iniciativa.

Una primera forma consiste en echarle ceniza "a la parte del cuello que se desprendió". Esto me trae a la memoria una observación recogida en Tantaqocha (La Mar) por el Instituto de Estudios Regionales José María Arguedas: "Dicen que para secar puquiales hay que echar sal y ceniza" (20.10.80). La sangre del cuello de la bruja sería así comparable al agua del puquial, lo que señala nuevamente la asociación de la bruja con la naturaleza (y en este caso, seguramente, con un lugar dañino de la naturaleza, como lo son muchos puquiales).

Otra forma de agarrar a la bruja, es utilizando un cuchillo o espinas. El cuchillo, y todo objeto se acero en general, es considerado normalmente como un instrumento de pròtección contra los poderes maléficos: algunos curanderos lo usan para "limpiar" a las personas, y sirve también para -haciendo con él una cruz en el suelo - evitar que la pacha agarre al viajero (ila bruja es asociada con la pacha mala?).

La explicación de las espinas no queda del todo clara en este relato, pero comparado con otras versiones se entiende perfectamente: por tener una larga cabellera, la cabeza se enreda en las espinas y queda prisionera, sin posibilidad de volver hacia su cuerpo, y por tanto condenada a morir, a menos que alguien la libere luego de un trato en el que ofrezca muchas riquezas (que posee al igual que la naturaleza, y particularmente la tierra). En otras versiones, algo similar sucede cuando la bruja suplica se le limpie la ceniza del cuello. Entendemos ahora por qué la cabeza no podía acompañar al viajero en el árbol: se enredaría en sus ramas.

La bruja representa así los peligros que corre quien se aventura fuera de su ambiente cultural. Pero el cuento nos indica que por su astucia el hombre no sólo se puede liberar, sino también puede sacar provecho de su lucha contra las fuerzas desconocidas y maléficas de la naturaleza. La relación con la naturaleza se muestra así similar a la relación con los demás hombres: cuando ella es propicia, se la debe respetar, pero cuando se muestra hostil, se la puede y se la debe engañar, obligándola a entregar sus tesoros.

El texto que viene a continuación forma parte de la autobiografía de María Magdalena Beingolea Guevara, presentada en 1981 por Victor Solier Ochoa en el marco de un curso de la Uńiversidad Nacional de San Cristóbal de Huamanga. La informante es natural de Ongoy (Andahuaylas) y tiene 93 años. Llegó a vivir a Ayacucho a la edad de 50 años. 


\title{
Qarqacha
}

\begin{abstract}
"Nosotros regábamos la huerla con el agua de una acequia. Cuando mi padre se fue a soltar el agua, yo me quedé en la parte baja de la acequia, ya era de noche. en eso se presentaron los qarquchas. Yo agarre ankukichka y les tirc y se quedaron ahi atrapados, al amanecer vi que era gente conocida, era un señor que vivia con su hija. Llorando nos decra que lo soltaramos pero no lo hicimos y al medio dia murió.

Los qarqachas salen solamente de noche, $y$ es su cabeza el que anda, no asi su cuerpo, v si no vuelve a unirse esa cabeza con su cuerpo hasta el medio dia muere el yaryacha. En Chingaray al trente de Pampas, hay muchos pacaes. Mi lio Guevara dice que agarro a un qarqacha ya que la cabeza del qurqucha se habia pegado a su hombro, el regresó con dos cabezas y mi tia al verlo se asustó, dice que lloraban las dos cabezas. Mi lio para separarse de la cabeza le dijo que queria coger los pacaes que estaban ricos y maduros a Muriacha (la cabeza del yaryacha). no le gustó la idea pero a tanta insistencia de mi tio la cabeza se bajo de su hombro y se sentó en un poncho, en eso aparecio un venado y la Mariacha pensando que era mi tio, al venado se pego en su lomo. Al ver esto mi tin bajó del árbol y escapo corriendo de miedo por temor que se le perara de nuevo la cabeza".
\end{abstract}

La segunda parte del relato es similar a la dos versiones ya analizadas y confirma lo que ya se hal dicho. Sill embargo, en la primera parte nos enteramos que la (abe/a voladora no es de una bruja. sino de un (parcjacha. per. sona incestuosa. El comportamiento de la cabeza es a pesar de cllo el mismo que en el caso de la bruja; se le puede agarrar de la misma mancra. tirandole esninis (ankukichka). !' se le cnginna subiendn al arhol frutero.

Segun las versiones mas communes. los (jar(jachas son personas que mantic. nen relaciones sexuales prohihidas. y yue salen de noche a recorrer el campo) bajo la forma de llamas. lo que parece significar que su conducta los reduce al range de los animales. (omparando estas versiones. no habria mucha diferencia entre convertirse en puro espiritu. en incro intelecto y rebajarse al nivel de la bestia. En ambos casos se rompe con la sociedad para asimilarse a la naturaleza.

(omparemos ahora las versiones prescntadis con el texto de Pani Paila que presentamos en nuestro articulo anterior. Para mayor facilidad del lec. tor. recordemos rápidamente los elementos del relato:

Un hermano y una hermana se escapan de un padie rico para vivir en una cueva. El hermano regresa periódicamente a sulasa para conseguir comida. Una noclie que robaba asi. es agarrado y golpeado. pero se escapa sin ser re. conocido. Vuelve herido donde su hermana y le miente contandole que ha sido perseguido por una zima. En otra incursión a la casa de su padre. el hermano es matado por éste que recién lo reconoce ya mucrto. El hermano re. gresa donde su hermana quien se escapa cuando se da cuenta que el se ha convertido en condenado, y con ayuda de la Virgen, se salva refugiándose en 
un convento de la ciudad.

El relato de la uma (la mentira del hermano) decía lo siguiente:

"Su hermana le preguntó qué le habia pasado y él dijo que cuando estaba volviendo, una uma le habra comenzado a seguir y tenia que escaparse por huacos y caminar por donde habia árboles y espinas para que no se le pegue, y la uma le cuidaba y estaba alegre porque más adelan te ya no habia nada, era pampa, pero en eso saltó un venado y la uma pensando que era él, se pegó al venado que se escapó a toda velocidad hacia el monte". (p. 200).

En el análisis del texto, habiamos visto que algunos estudiantes asociaban al hermano de Paula con el carcqacha. y esto reforzaba en ellos la idea de la existencia de una relación de incesto entre hermanos. Otra versión recogida desde entonces me confirma esta interpretación. Esto nos permite precisar el sentido de la mentira del hermano. Habiamos dicho que "al mentir, el hermano dice la verdad sobre su propio futuro: el huayco, las espinas y el venado que lo defienden de la uma según su mentira son análogos al ichu, las espinas, la laguna, y el cura, que defenderán a su hermana de él mismo con su cabeza cortada". (p. 203). Si algunos asocian la uma con el qarqacha, entonces el hermano-farcfacha y la uma tienen en este contexto un similar significado simbólico, y la mentira del hermano anticipa efectivamente su propio futuro.

Comparando las demás versiones con el relato sobre la uma inserto dentro de Pani Paula, observamos una diferencia importante: en este caso, la uma no logra pegarse al hombro de la persona perseguida, del mismo modo como el hermano no logrará alcanzar a Paula. Los demás elementos del rela to son similares a las otras versiones, y seguimos observando de paso la función protectora de los árboles y las espinas.

La modificación del relato nos hace ver que el discurso mítico es un len. guaje vivo que se transforma para adaptarse al objetivo del narrador: en este caso, utilizarlo como elemento que anuncia el desenlace de la narración glo. bal.

Para concluir con las cabezas voladoras, vemos en todas las versiones el engaño aparece moralmente justificado, como una forma de defensa contra quien ha roto las reglas de reciprocidad con la sociedad. Se engaña exitosamente utilizando la contradicción en que se encuentra el sujeto para. sitario y explotador: para poder recibir el alimento de parte de su siervo, la uma tiene que concederle suba al árbol, y para esto tiene que despegarse. Si cl engaño es exitoso, se rompe la relación de servidumbre: el hombre vuelve a conquistar su libertad, $y$ en algunos casos puede obtener muchas riquezas extorsionando al extorsionador. 


\section{El cerro castiga al mentiroso}

A la inversa del engaño moral y socialmente justificado, en Pani Poula la mentira con seres que se encuentran en relación de reciprocidad era parte de todo un proceso de ruptura con la socicdad, que conducia al castigo y a la muerte y condenación. Fsta misma idea, la encontramos nuevamente en el texto siguiente. que fue presentado por (juido Tineo Lujän, estudiante de la Escuela Normal Superior de Ayacucho, durante el año 1981. El lo escucho de su padre. Juan Jose Tineo Munarriz.

\section{El Milagro del Cerro}

"Esta es la historia de un hombre pobre que se dedicaba a cuidar mulas de un hombre rico y avaro que vivia en Carmen Alto. Resulta que cierto día recibió como de costumbre una cantidad de mulas para pastear; pero a la hora de devolver se dio cuenta de que le faltaba unas mulas, de lo cual informa al dueño quien lo amenaza con matarlo y después de golpearlo lo arrea y le dice que vaya a buscar; hecho esto, el hombre pobre sale llorando y desesperado. Se dirige al sitio donde pasteó durante el dia: sin lograr localizar al perdido, se pone a deambular y sin darse cuenta llega cerca de unas cuevas que se encuentran en la parte este del cerro Acuchimay, que segun la creencia de la gente antigua cra la puerta del cerro. Ahí se quedó sentado, pero al rato ve con asombro que la puerta se abría, luego salió un hombre alto y blanco, quien le pregunta que es lo que hace en ese lugar y a tan altas horas de la noche. A lo que el hombrecito le responde contándole todo lo sucedido.

El hombre salido del cerro le invita pasar adentro del cerro, que era un mundo maravilloso, lleno de jardines y flores bellas. Ya adentro le dice que espere, porque para poder ayudarlo necesitaba la ayuda de los demás cerros. Asr es que se entabla Ia siguien te llamada:

Acuchimay le llama primero al cerro Rasuhuillea $y$ le dice:

- Rasuhuillca. . a acjui hay un hombre que necesita de nuestra ayuda, tú zqué le envias?, a lo que $R$ asuhuillca le responde:

- Yo solo le mandare un saco de manzanas, que a continuación llegará a esa.

Luego llamo al cerro Apacheta y le dijo:

- Apacheta. . aqui hay un hombre que necesita nuestra ayuda, tu ¿qué le das? A lo que le respondio: yo le enviare un saco de maiz morocho.

$Y$ por fin el se quedo satisfecho, y al final le dice: yo solo te dare un saco de maiz blanco, pues entonces esperemos un rato.

Despues llegaron los dos encargos de los cerros, que venian cargados en una vicuña y la otra en un toro negro. Ya despues el cerro Acuchimay se encarkó de entregarle al hombrecito quien agradecido se fue llevando consigo los obsequios. En su casa, éste le cuenta a su esposa, y le hace ver todo lo que habia llevado, pero su asombro fue grande cuando se dio cucinta eran bolas de oro y plata.

Ya de madrugada. el dueño de la mula fue a su casa, a preguntar si habia encontrado o no; donde el hombrecito le salió al paso y le dijo de que no habia encontrado. pero si le podra pagar el precio de su mula; a lo que el hombre le dijo el valor, este 
hombre entró a su casa y trajo una bola de oro y le dio. El dueño de la mula se quedo asombrado y le pidio explicaciones de la procedencia de dicho metal; a lo que el hombrecito le informa el cómo lo habra obtenido.

Como este hombre era un avars y ambicioso, planeó también obtener. Así es que se alisto para ir, y por la noche se fue al lugar indicado y esperó a que se abriera.

Ya llegada la hora la puerta se abre, sale el hombre del cerro y le pregunta el moti. vo; éste finge llorar y le dice que su mula se perdió y por eso él está buscando. A lo que el hombre le hace pasar dentro del cerro y pide que espere un rato, puesto que el va a llamar a sus colegas. El llamado empieza:

- Rasuhuillca. . . aqui hay un hombre que pide tu ayuda; a lo que éste le contesta y dice enviarle unos hermosos cuernos de toro.

El hombre escucha y piensa que serán cuernos de oro.

Luego llama a Apacheta.

- Apacheta. . hay un hombre que pide tu ayuda; éste le contesta y le dice enviar una cola de caballo.

El hombre piensa que será cola de plata.

$Y$ al final el cerro Acuchimay le dice: yo te daré un hermoso pellejo de borrego.

El hombre piensa que será de pura plata.

Luego esperan la llegada. Una vez recibidos los encargos, le entrega y le dice: Mira, para que no te dificultes, yo te los voy a poner, y asr te irás tranquilo; y dicho esto. le pone los cuernos en la cabeza, el pellejo en la espalda y la cola atrás. Ya puesto, el hombre se va conten to hasta su casa; pero al llegar se sorprende, porque ni el cuerno, ni la cola, ni el pellejo quieren desprenderse, y desde ese dra vivía avergonzado y escondido, hasta que murió desesperado, pagando de esa manera su ambición".

Este relato trae muchos elementos que ayudan a comprender mejor los textos sobre Wamanis analizados en nuestro artículo anterior.

Como en muchos otros relatos, el Wamani (espíritu del cerro) aparece como un hombre alto y blanco. Sale por una cueva, que es la puerta del cerro. Dentro del cerro se encuentra "un mundo maravilloso, lleno de jardines y flores bellas". Como ya lo vimos en otro relato (1982, pp. 197, 198), los cerros se ayudan entre si y actúan de noche, mandándose riquezas unos a otros. Nuevamente aqui, la vicuña aparece como un animal dal Wamani, que carga sus riquezas. Vemos ahora que el toro negro también puede cumplir este trabajo. Esto podria estar ligado al hecho que el Wamani es quien vela por la reproducción del ganado. Quizá pertenezca al Rasuhuillca, que es el cerro más importante de la zona, y que sin duda por ello es invocado en primer lu. gar.

El hombre pobre recibe agradecido los regalos de los cerros, que son frutos de la tierra. Los Wamanis en efecto no sólo son dueños del ganado, sino también de la agricultura. Pero estos frutos son en realidad bolas de oro y de plata, los tesoros minerales que pertenecen al Wamani. Se deja entender que los frutos de la tierra son regalos del cerro, y que son un tesoro inestimable 
que es otorgado a quienes se muestran respetuosos de las reglas con los Wamanis y con la socicdad.

El avaro en cambio, que no respeta las normas sociales de intercambio y se ha convertido en explotador. se acercad al cerro para enganarlo: "finge llorar y le dice que su mula se le perdic y por eso el estij buscando". Los cerros van mandando entonces los distintos atributos de animales. en tanto son dueños de ellos. Se confirmaria aqui que el Rasuhuillea es duenos del toro (envia cuerno de toro) y ademis que por su importancia se esperal que su regalo se convierta en oro lcomo posiblemente. aunque no se diga cxplicita. mente, fueron las manzanas las que se convirticron en bolas de oro).

Como consecuencia de su intento de enganar al cerro. el avaro se ve conn. vertido en una mezcla de hombre y animal. De nuevo encontramos la repre. sentación simbólica y real para cl narrador de lo que es el avaro: un hom. bre que se ha puesto al lado de la anticultura. convertido en un ser en quien se confunde el animal con el hombre. Este es su castigo, que lo aparta definitivamente de la socicdad. lo que conduce a su muerte.

Engañar a un ser antisucial y parasitario (la uma) resulta un acto positi. vo y moralmente bueno. Es la ünica forma de salvar la vida, y cn algunos cadsos incluso se pueden obtener riquezas.

En cambio, engañar a un ser que es protector de la comunidad. como es el Wamani, es un acto despreciable que ocasiona la perdida de la vida social y con clla de las riquezas. y que lleva a la muerte.

\title{
Cuando el engaño no resulta
}

El siguiente texto nos fue proporcionado en 1981 por Fidgar Jorge Viranco Huamani, alumno de la Escuela Normal Superior de Ayacucho. Le fue contado por su abuelo Julio Vivanco T., procedente de la provincia de La Mar.

\section{Los qalañuñus}

\begin{abstract}
"Cuentan que en tiempos de nuestros antepasados hacian su aparición con frecuencia estos qalañuñus que causaban cierto terror a las personas, que consistia en dos personas, varón y mujer, completamente desnudos.

$Y$ cuentan que habia un hombre que era propietario de grandes extensiones de tierra en las que cultivaba en gran cantidad el tubérculo que es la papa. Y éste hacia cuidar estos cultivos con un guardián que se ubicaba en un lugar estratégico para po. der divisar toda la extensión del cultivo y asi sucedió una noche a las doce de la noche hacen su aparición estos personajes extraños (qalañuñus), al ver esto el guardian de miedo se escapa y le cuenta a su patrón, y éste no le cree. Al dia siguiente hacian
\end{abstract}


la inspección de los cultivos y encontraban que los cultivos habian sido robados. Al ver esto el dueño se queda a cuidar personalmente y como de costumbre a media noche hacen su aparición estos personajes desnudos, y el dueño que no creia se enfrenta con su honda y logra su objetivo en que a uno de ellos lo hace agarrar y se cae. Entonces al capturarlo se da cuenta que todo era un juego, que estos qalañuñus distraian al guardiän mientras sus demás cómplices robaban".

El presente relato se sitúa en un nivel distinto a los anteriores, pues es una visión critica sobre la utilización social que se puede hacer de los cuen. tos.

Llama la atencion que estas "dos personas, varón y mujer, completamente desnudos" puedan causar terror. Sin duda son considerados seres de la anticultura, pues andan de noche y sin ropa. mientras el runa debe andar vestido y de día. Quiza se trate de personas que tienen relaciones incestuosas, al igual que los carc(achas. Lo seguro es que estos qalañuminus ${ }^{4}$ ponen en peligro las normas sociales.

La Mar es zona antigua de haciendas. Este relato nos cuenta como un gran propietario es engañado para poder robarle. Desde el punto de vista de los ladrones (quizá los propios peones de la hacienda, o comuneros vecinos) debe ser justificada su acción frente a un hombre rico. cs una forma de obtener riquezas de un hombre "malo". Actúan pues como lo harian con una uma.

Pero el engano sólo funciona con el guardián, campesino como los ladrones. El patrón en cambio no cree el cuento. Si cultiva grandes extensiones de papa, es porque está ya fucrtemente ligado al mercado y al mundo moderno por lo que debe tener cierta prevención contra las "supersticiones". Pero se debe también recordar que cuentos de este tipo fueron muchas veces inventados por los hacendados para proteger sus cosechas y asustar a los campesinos. De cualquier modo, el engaño es descubierto porque la victima no comparte la creencia campesina.

El engaño frustrado nos muestra que los ladiones se equivocaron en la forma de engañar, pero queda intacta su intención de burlar al dueño. Lo malo no es haber querido engañar, sino haberse dejado agarrar.

La ética andina no pone pues la sinceridad por encima de todo como si fuera sicmpre una virtud. Decir la verdad es una exigencia entre amigos, entre quienes mantienen vínculos de reciprocidad, y es entonces una necesidad práctica que permite la colnesión social. Con los demás, con los que están fuera de estos vínculos de solidaridad, la mentira, la burla, la hipocre. sia, son normas reconocidas. 


\section{El problema de la verdad}

\section{La autenticidad en los relatos andinos}

Los mitos andinos hablan por medio de símbolos, pero una condición de su eficacia es que sean creidos: la uma representa la anticultura y fortalece por oposición los vínculos sociales sólo en la medida que es un ser que es visto como realmente existente.

Por ello, muchos narradores precisan el lugar donde suceden los acontecimientos ("en Sucahuaycco", "en el camino de San Miguel a la Selva", etc.). Se aclara también si el hecho ha sido vivido por el propio narrador, si lo ha sido por un pariente o por otra persona conocida, o si se trata simplemente de algo que la gente cuenta.

El quechua distingue claramente el nivel de confianza que tiene el narrador en cuanto a la seguridad de lo que afirma. Con el sufijo $-m i(0-m)$, "el hablante expresa que su enunciado es de primera mano; que el juicio que emite se basa en su experiencia y, por ello, asume responsabilidad por él" (Soto, 1976, p. 123). En cambio, el sufijo si (o s) "indica que el hablante refiere algo basado en la autoridad de otras personas; que no es de su experiencia personal" (Soto, 1976, p. 124). La transposición al castellano ayacuchano de la idea expresada por el sufijo -si explica la repetición constante de la palabra dice ( $n$ ), no acompañada de sujeto.

De ese modo, la autenticidad de los hechos relatados descansa en el testimonio personal, y el destinatario podrá evaluar la veracidad de lo que escucha de acuerdo al grado de confianza que le merece el narrador, y a nivel de confianza que tiene éste mismo en la autenticidad de los hechos que cuenta.

En este contexto, el mito, que puede tener una estructura común básica, varía según las circunstancias (por ejemplo cambia el tipo de árbol en los relatos de uma), y también según el mensaje que se quiera transmitir y las características del narrador. A la vez que insiste en la realidad de los hechos contados (o en su duda sobre esta realidad), el narrador reinterpreta el mito de acuerdo a su propia experiencia personal, porque los hechos no le interesan sino por lo que significan.

En estas circunstancias, es totalmente inexistente la preocupación por la autenticidad del relato como tal, en tanto que texto, a la manera que un historiador se preocupa por la autenticidad de un documento. No es pues solamente por su carácter de relatos orales que los mitos andinos desconocen por completo en su difusión, lo que entenderíamos por autoría individual de un texto. 


\section{El quehacer científico}

La lógica del trabajo científico en cambio incluye una crítica de la autenticidad de las fuentes. Pero hay más. Según los estudios de la sociología de la ciencia, uno de los mayores incentivos psicológicos que tiene el investigador es la búsqueda del reconocimiento de los demás científicos ${ }^{5}$. Este prestigio se consigue centralmente mediante la publicación de trabajos originales. La fuerte competencia entre científicos hace que todos cuiden muy celosamente su información y sus avances, por temor a que otros les "roben" sus trabajos. Los plagios y pleitos por cuestiones de prioridad son por ello muy frecuentes.

Merton, uno de los primeros en estudiar el fenómeno en Estados Unidos. señala lo siguiente:

"Los litigios, los reclamos de autoaseveración, el secreto por mieło a ser ganado, indicándose solamente los datos referidos a la hipótesis, los falsos cargos de plagio, inclusive el robo ocasional de ideas - todo eso se ha dado en la historia de la ciencia y se puede pensar como comportamientos desviantes que responden a un contraste entre el énfasis enorme que pone la cultura de la ciencia en la originalidad del descubrimiento, y la dificultad que experimentan actualmente muchos científicos en hacer un descubrimiento original". (Merton, 1973, p. 323).

\section{Los malentendidos de un choque cultural}

Todos estos elementos nos sirven para iniciar una reflexión sobre lo que sucede cuando un científico social se encuentra con un informante andino. Está claro que si no se logran establecer relaciones interpersonales positivas, el científico social corre el peligro de ser considerado como alguien que es permitido engañar (así como se engaña a la $u m a$ ) porque está fuera de las relaciones sociales que comparte el informante. Salvo en el caso de una in tegración total en una comunidad (que tiene sus ventajas y sus límites), siempre estará presente ese riesgo, que no debe inhibir en la investigación sino simplemente llamar la atención sobre la necesidad de una recepción crítica de la información.

Controlado este primer riesgo, queda sin embargo pendiente un segundo problema: el informante no transmite literalmente lo que ha escuchado, sino le da su propia interpretación. Esto es muy notorio en las traducciones que hace del quechua al castellano. Aquí no hay intención de engañar, simplemente el informante no percibe la importancia que puede tener para el cien. 
tifico social la versión original tal cual ha sido expresada por el quechuahablante. Una "mala" traducción (en el sentido de una traduccion no exactamente fiel al original) no implica necesariamente un conocimiento insuficiente del quechua, ticne que ver más bien con un desinterés por lo que representa un texto "auténtico". Al igual que cualquier otra persona, el informante está interesado por reproducir el contenido de lo que él mismo ('ntenclio.

Naturalmente, si el informante es andino, su mancra de relatar el mito escuchado tambien es "autentica" si lo que buscamos es analizar la estructura del pensamiento andino en general. En este calso la informalcion recibida es vilida.

En cambio, si buscamos captar la mancra particular cómo distintos sectores sociales expresan el mito, serii necesario un riger mucho mayor enl lat recopilacion de los datos, y en estos casos la grabadora se impone.

El malentendido. como gueda claro, surge en base a la confusicin entre dos maneras de interesarse en el mito: la del informante. que soilo se intereSa por la verdad del contenide tal como lo entendici. y eventualmente por saber si lo que se cuenta es cierto o no: y por otro lado el interis del cientifico social por saber ackemas si lo yue dice el informante es efectiva y exiactalmente lo que cuentan los campesinos entre si. y por asegurar que la fuente de informacioin senalada es autentica.

Un ejemplo concreto ilustranai esta situacion. En nuestro articulo anterior presentamos el andiasis de una serie de textos réogidos por estudiantes. (uando salici a la vental la revista. se descubrici que uno de los tevtos no cra producte de unal entrevistal realiaala por una estudiante. como creiamos, sino era un texto escrito originalmente por Ana Mayer y presentade por la estudiante en base a una adaptación y traduccioin al quechua del Centro de Investigación de Linguistica Aplicada de San Marcos. Se trata del texto: "Nawpa runakunapa awanan (El Telar de los Antiguos)".

Fuimos asi engañados en cllanto a la fuente de informacion. pero por otro lado no cabe la menor duda que el texto tiene un contenido profundamente andino: $y$ es precisamente en tanto forma parte de una lógica andina general que nos intereso. L:I "engaño" de la alumna refleja que ella aun no ha logrado penetrar en todo el rigor del trabajo cientifico, pero no invalida su información: la sola clección del texto (por lo demas modificado por ella en algunas partes) supone cierta identificacion con el mismo: y la estudiante pensó. con justa razinn. yue el texto presentado constituiria un buen material de trabajo en el marco de un análisis de mitos andinos. En esto pues no hubo engaño.

El modo andino de conocer no admite derechos de autor. Ni en su tecno- 
logía y conocimiento de la naturaleza, ni en su visión de las relaciones sociales. Esto no significa que todos los conocimientos estén socializados. El brujo. el curandero, el ponge del Wamani. guardan celosamente sus secretos. El saber sigue siendo poder, aunque sea puesto al servicio de la comunidad.

Con la rápida transformación y mercantilisación del campo. sin embargo. los conocimientos antiguos ya no son suficientes. En las comunidades campesinas se van incorporando nuevas tecnologias y nuevos conocimientos. que pueden ser aprendidos por todos. Cuando la comunidad logra lortalecerse, como viene ocurriendo en muchas partes, es posible que desaparczian los celos en la transmisiún del cunocimiento. y ésta es una lección que nos debe scrvir a todos. 


\section{NOTAS}

1. Szemiñski, Jan y Ansion, Juan (1982), "Dioses y Hombres de Huamanga", en Allpanchis, No. 19,' Cusco, pp. 187-233.

2. En éste como en los demás tex tos, mantuve la redacción original, limitándome a corregir la ortografía española y unificar el quechua rectificando la puntuación sólo en los casos necesarios.

3. Soto Ru1z, Clodoaldo: (1976) Diccionario Quechua Ayacucho-Chanca, Min. de Educación - IEP, Lima.

(1979), Quechua. Manual de Enseñanza IEP, Lima.

4. qalañuñu: seno (de mujer) desnudo.

5. Véase: Merton, R obert K. (1973). The Sociology of Science. Theoretical and Empirical Investigations (ed. N.W. Storer). The University of Chicago Press, Chicago. $Y$ particularmente, en esa obra: "Priorities in Scientific Discovery-1957". pp. 286-324. 